\title{
Erratum to: 3D thermal history and maturity modelling of the Levant Basin and its eastern margin, offshore-onshore Lebanon
}

\author{
Samer Bou Daher ${ }^{1}$ - Mathieu Ducros ${ }^{2}$ Pauline Michel ${ }^{3}$. Nicolas Hawie ${ }^{4}$. \\ Fadi H. Nader ${ }^{2} \cdot$ Ralf Littke ${ }^{1}$
}

Published online: 9 July 2016

(C) Saudi Society for Geosciences 2016

\section{Erratum to: Arabian Journal of Geosciences DOI 10.1007/s12517-016-2455-1}

The original version of this article, unfortunately, contained errors.

The images of Figures 8 and 9 found in the online PDF did not match with the HTML version. In the PDF, continued images of Figs. 8 and 9 were duplication of panel "b" of each figure.

The correct images are presented in this article.

In addition, "Upper Triassic," which is found in the caption of Figure 8 was corrected to "Lower Triassic" and is now reflected in this paper.

Lastly, the name Samer Bou Daher, though appearing correctly in the published version, appears as S. B. Daher in indexing

The online version of the original article can be found at http://dx.doi.org/ 10.1007/s12517-016-2455-1.

Samer Bou Daher

samer.boudaher@emr.rwth-aachen.de

1 Energy and Mineral Resources Group (EMR), Institute of Geology and Geochemistry of Petroleum and Coal, RWTH Aachen University, Lochnerstrasse 4-20, 52056 Aachen, Germany

2 Geology Department, Geosciences Division IFP Energies Nouvelles, $1 \& 4$ Av. de Bois-Préau, 92852 Rueil-Malmaison Cedex, France

3 Geochemistry-Petrophysics Department, Geosciences Division IFP Energies Nouvelles, 1 \& 4 Av. de Bois-Préau, 92852 Rueil-Malmaison Cedex, France

4 Beicip-Franlab, 232 avenue Napoleon Bonaparte, 92500 Rueil-Malmaison, France sites instead of S. Bou Daher. The metadata was updated to display the name correctly in indexing sites.

The original version of this paper was updated to reflect the changes stated on this erratum. 

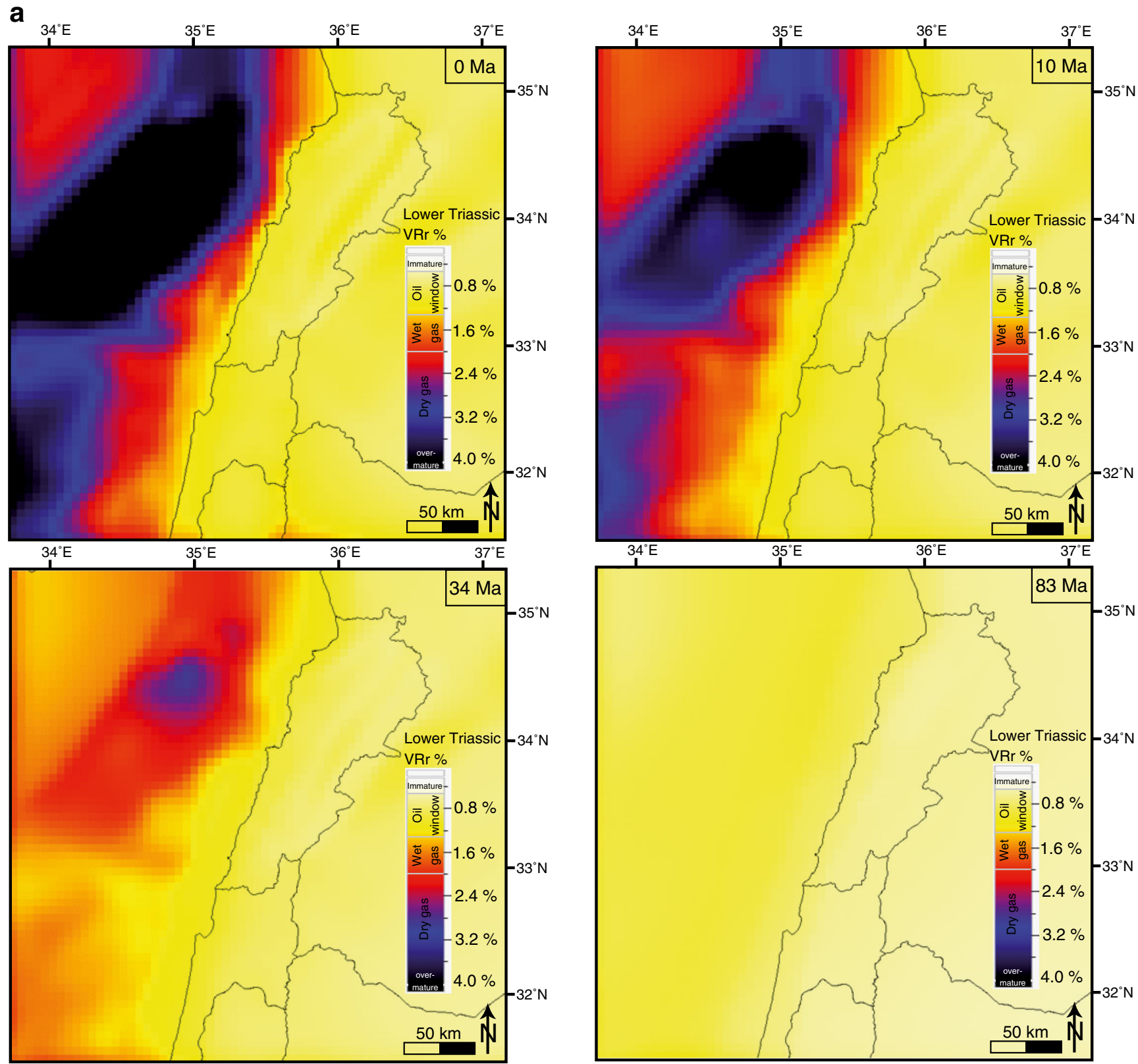

Fig. 8 Calculated vitrinite reflectance map for a Lower Triassic, b Kimmeridgian, c Cenomanian, and d Campanian. e, f Cross sections AA' and BB', respectively, showing calculated vitrinite reflectance at the present day (see Fig. 1 for location) 
b
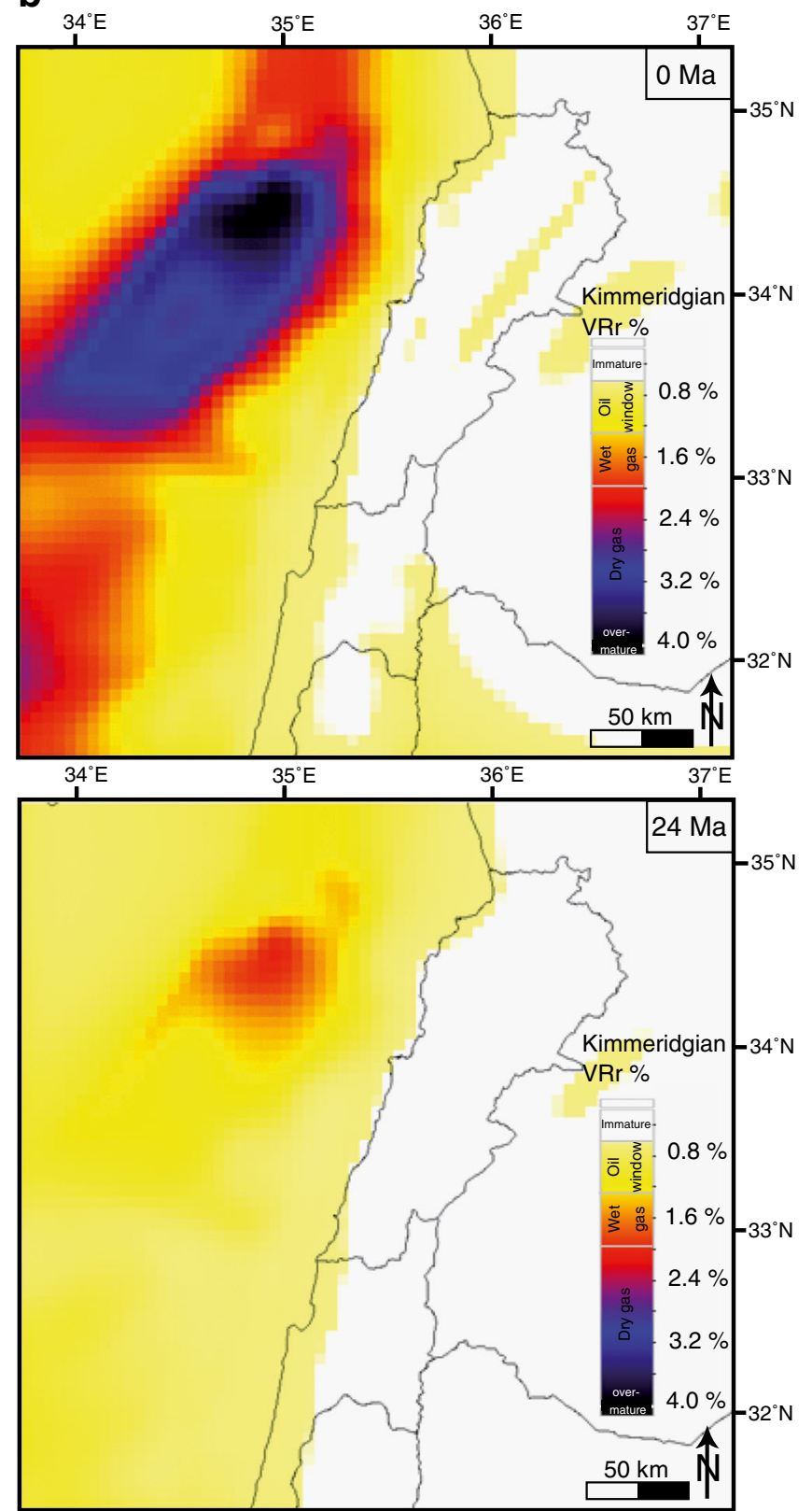

Fig. 8 (continued)

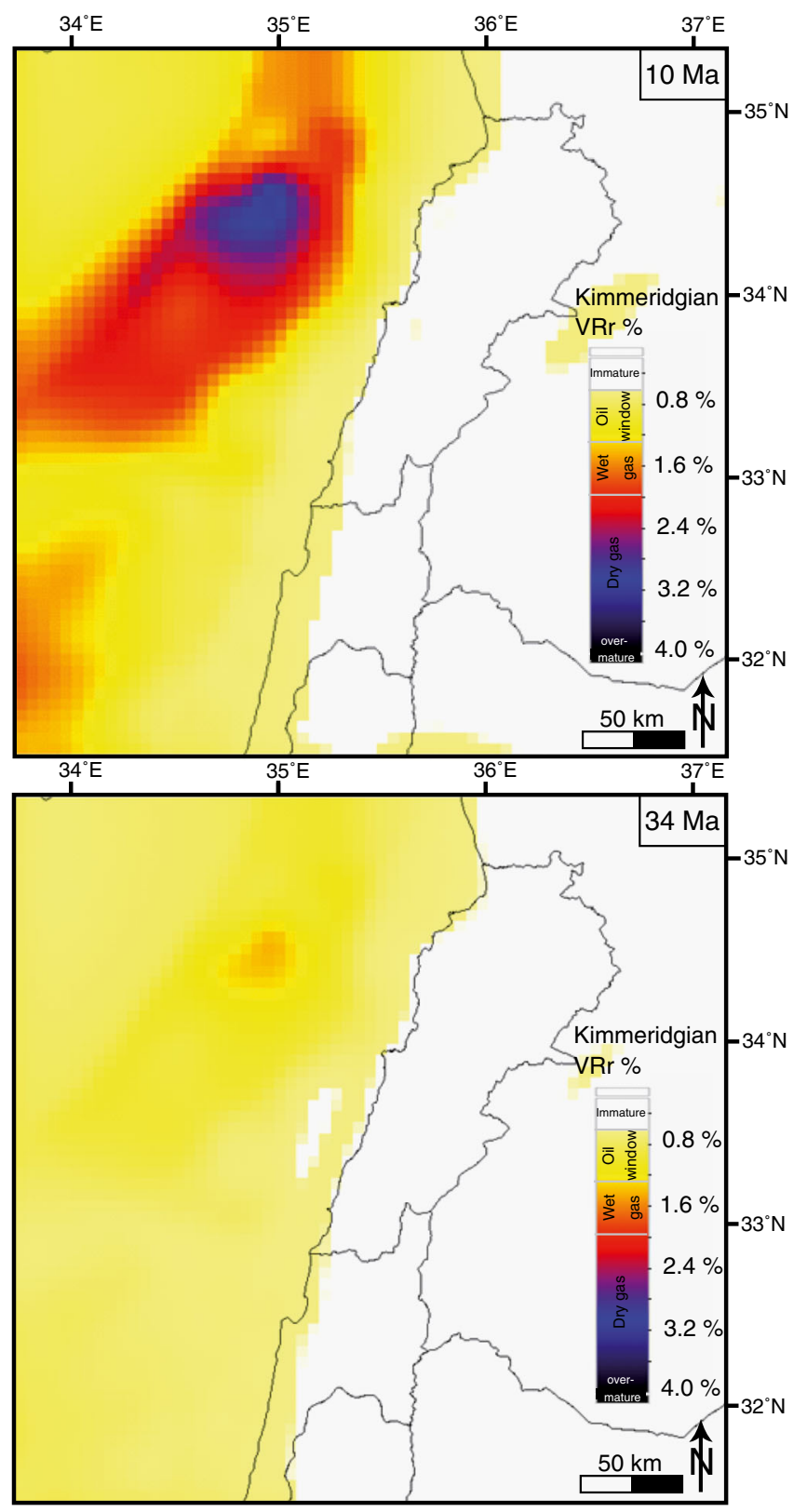


C
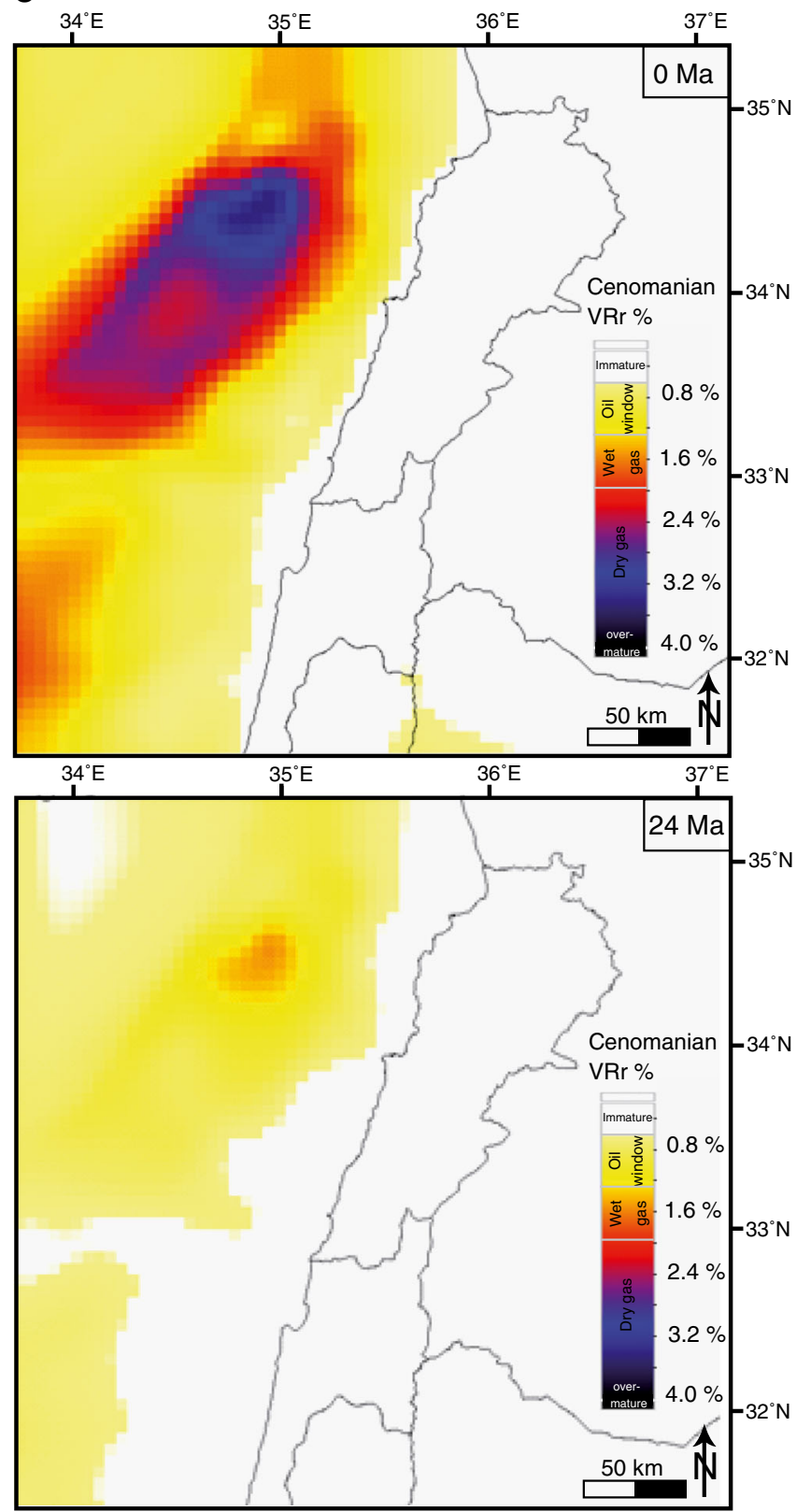

Fig. 8 (continued)

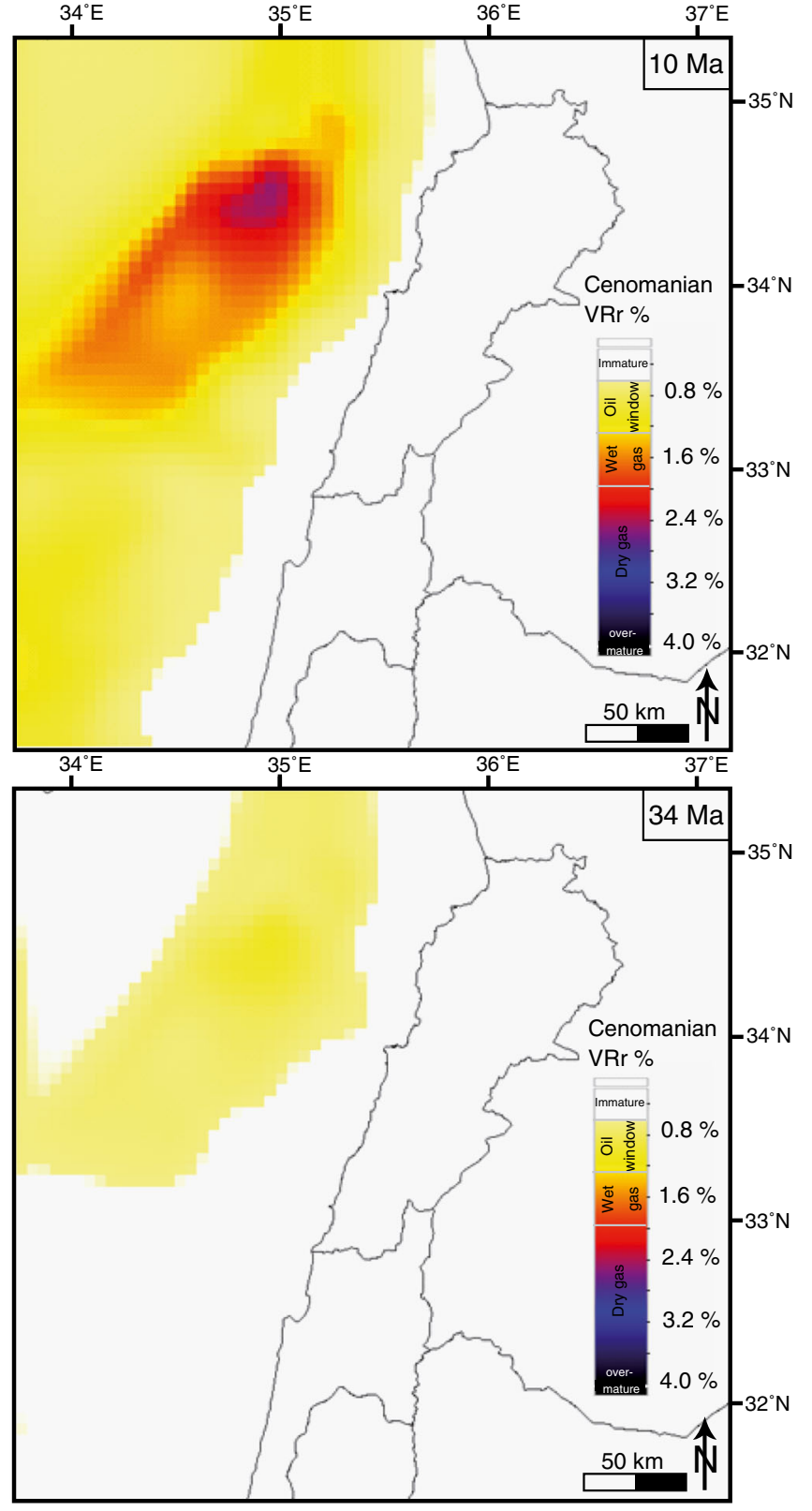


d
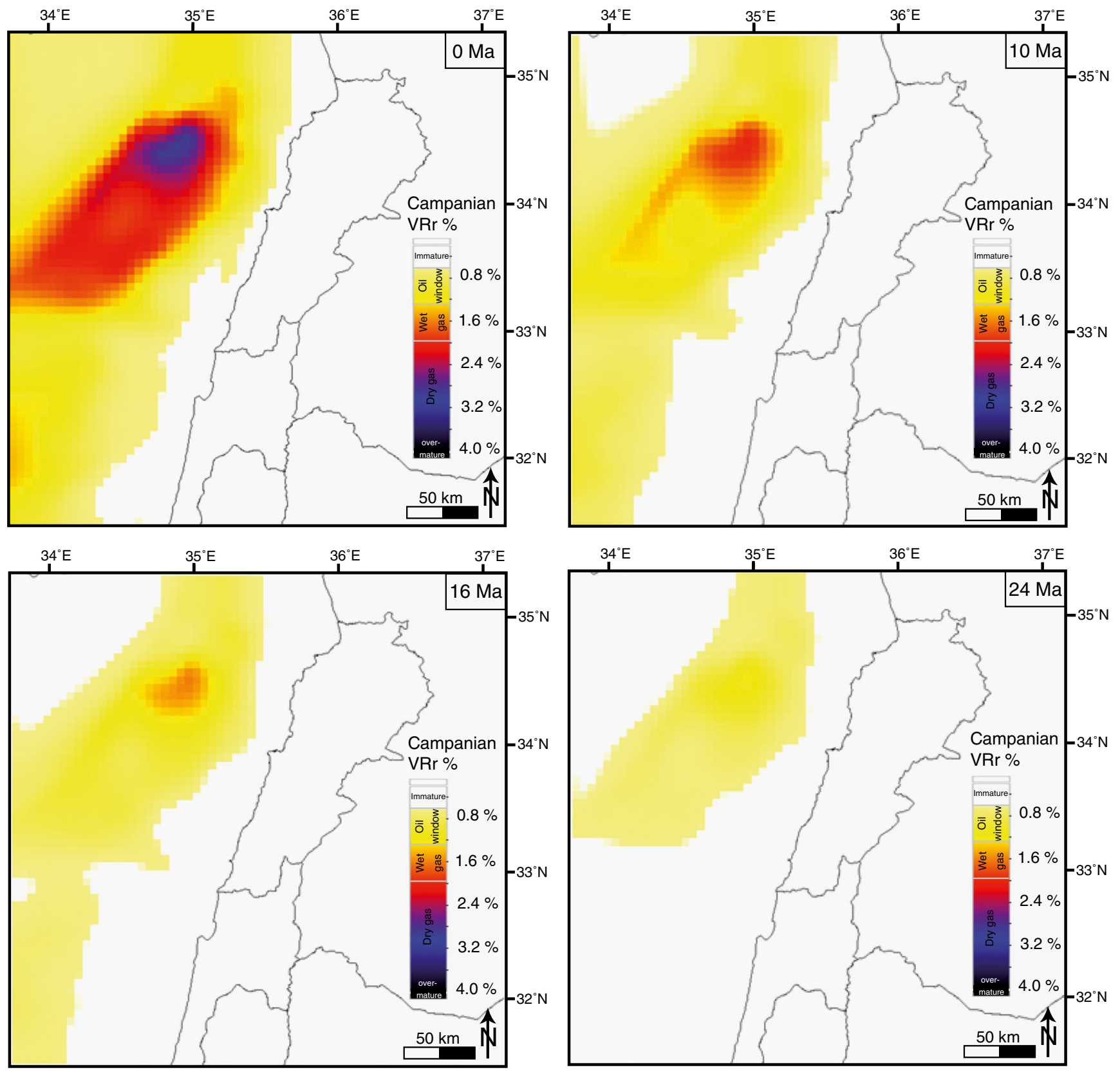

Fig. 8 (continued) 

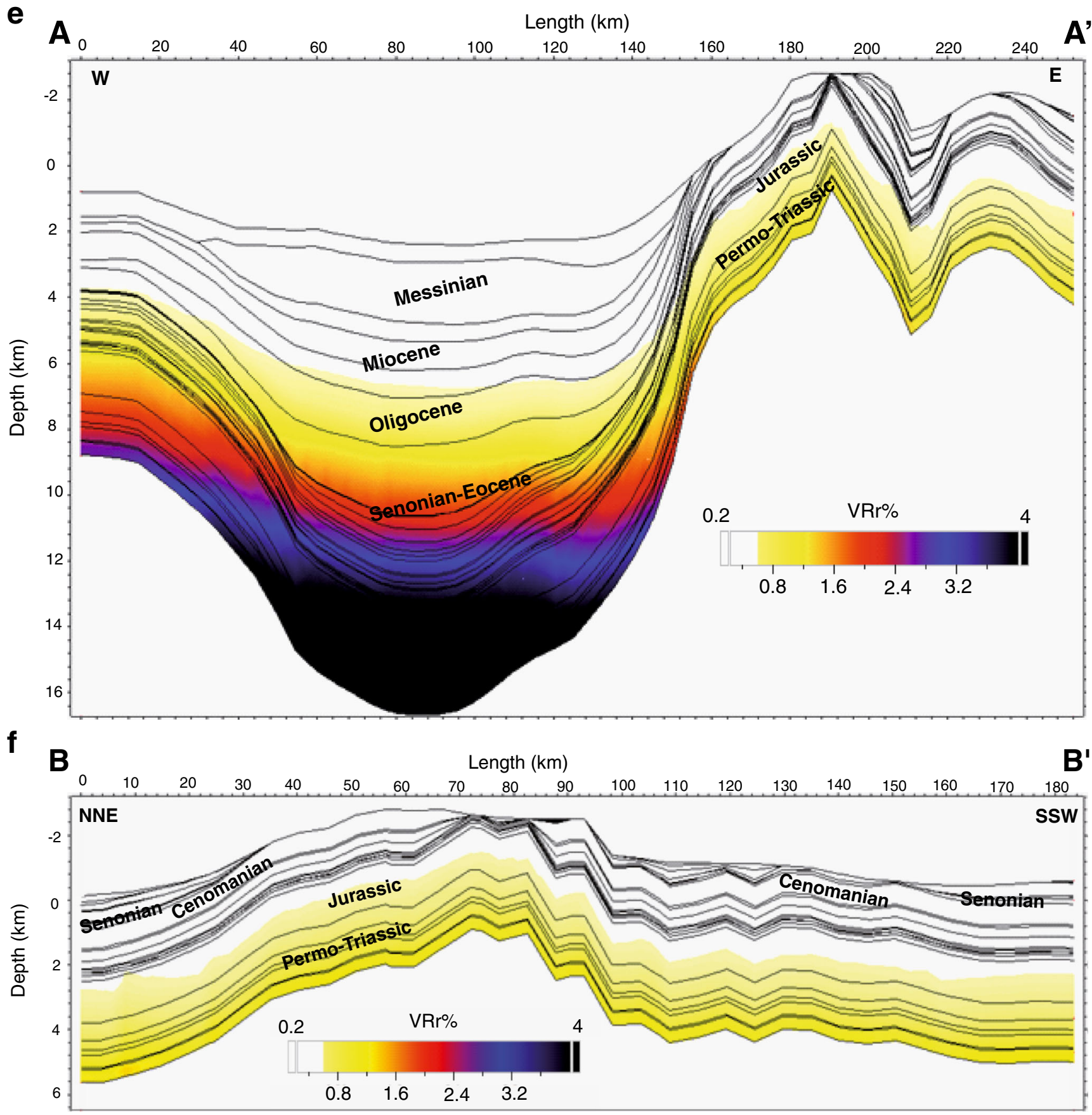

Fig. 8 (continued) 
a
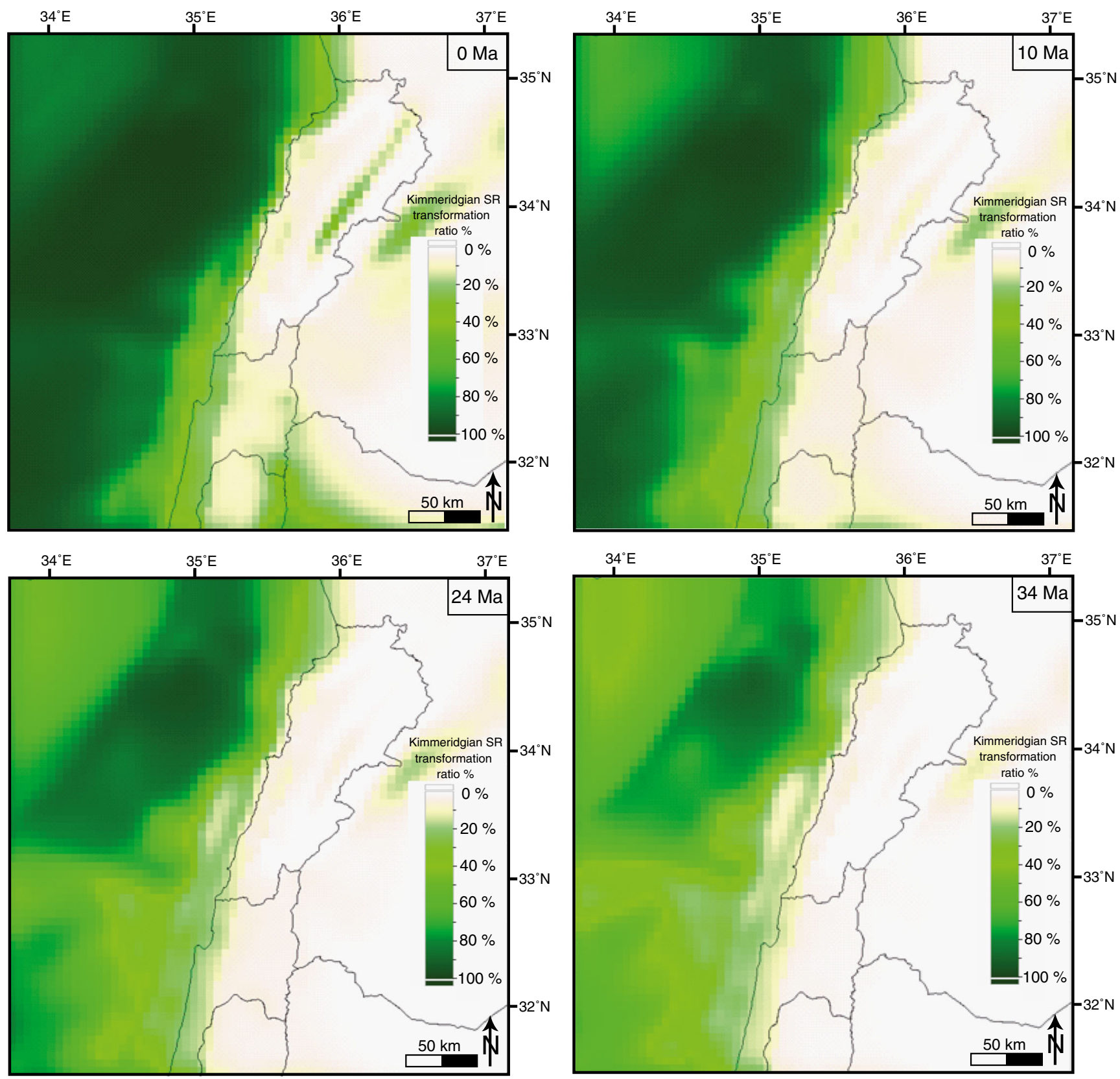

Fig. 9 Source rock transformation ratio maps for a Kimmeridgian, b Lower Cretaceous (Neocomian), c Campanian, and d Paleocene 
b
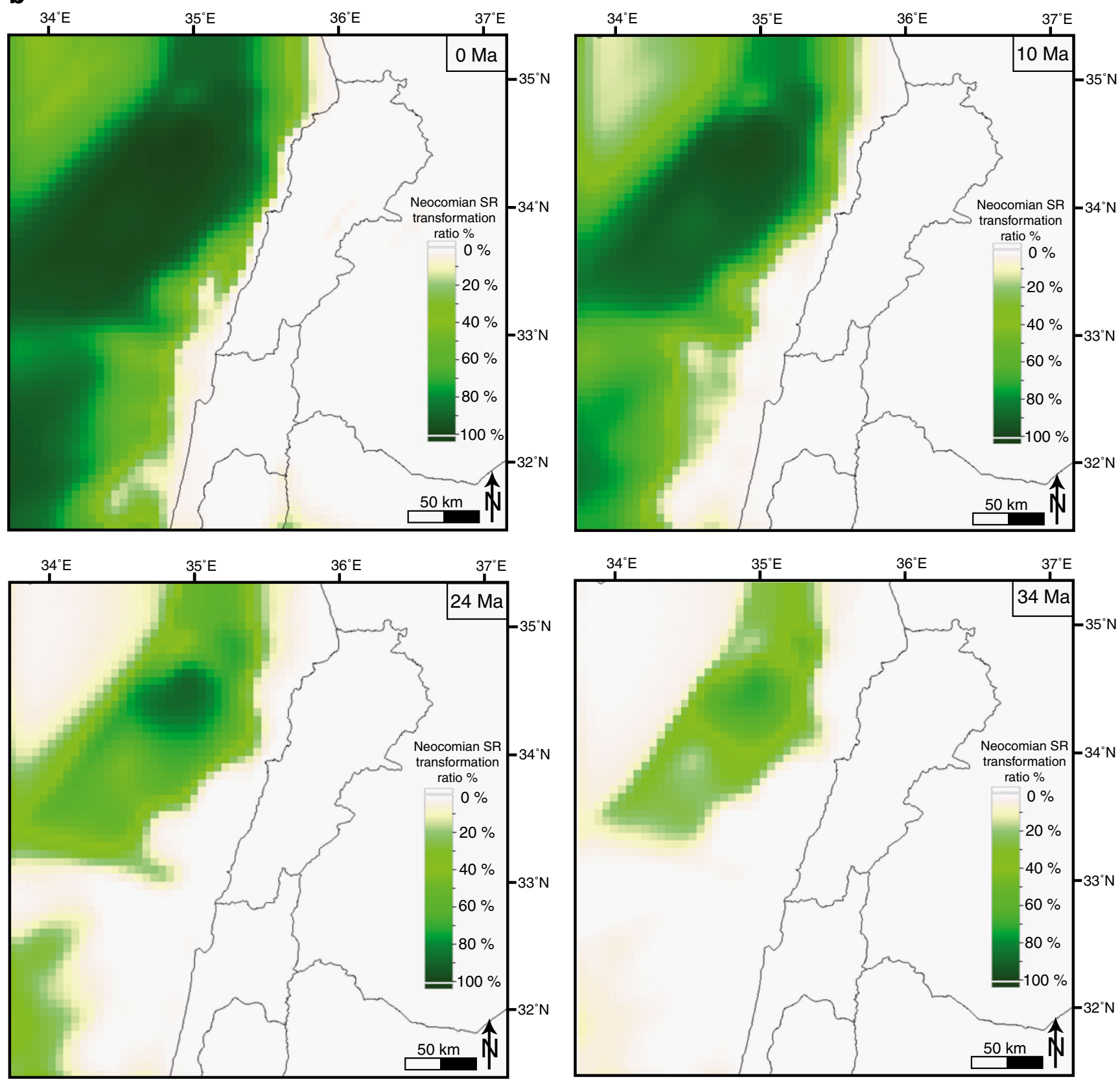

Fig. 9 (continued) 

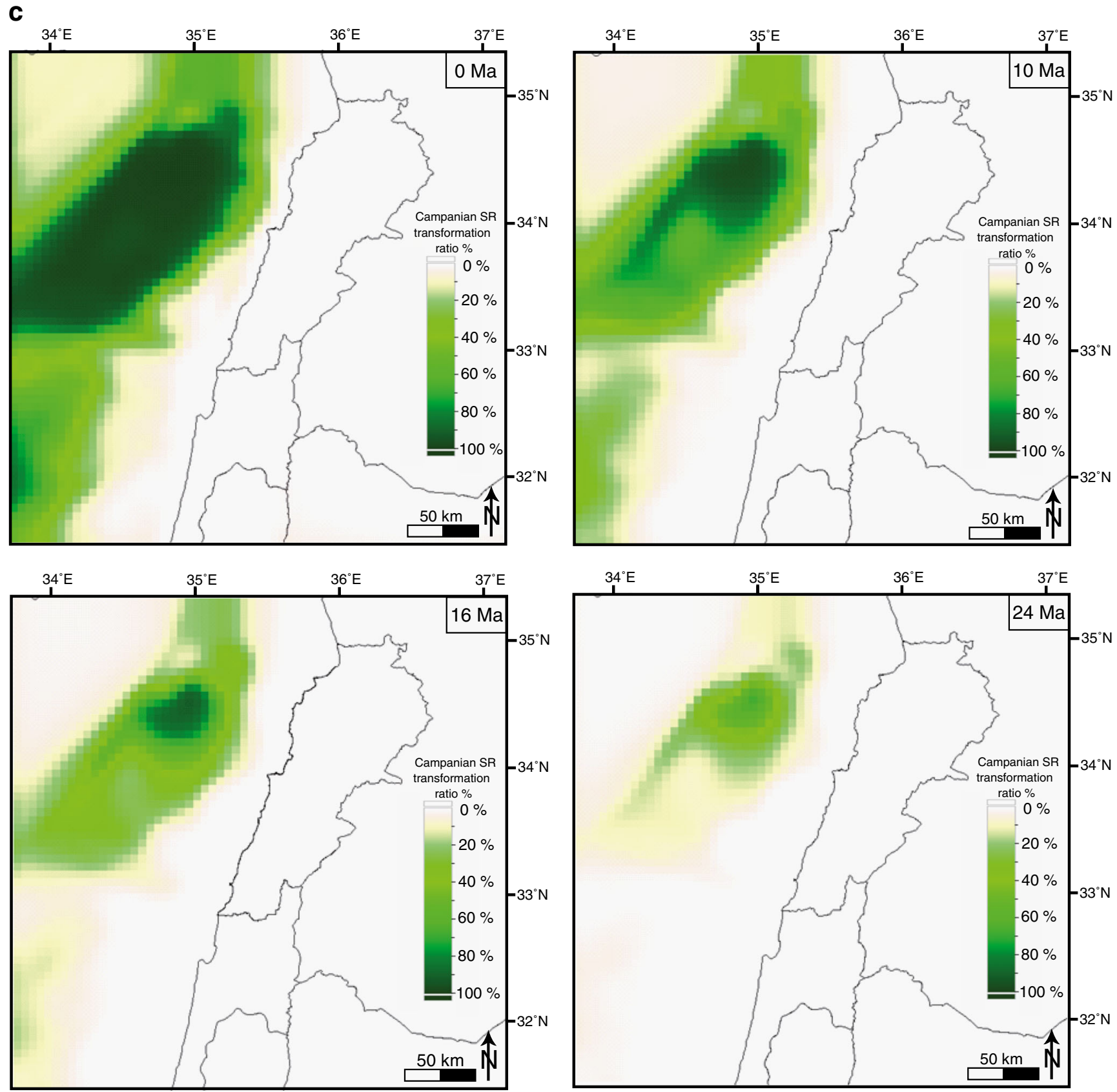

Fig. 9 (continued) 

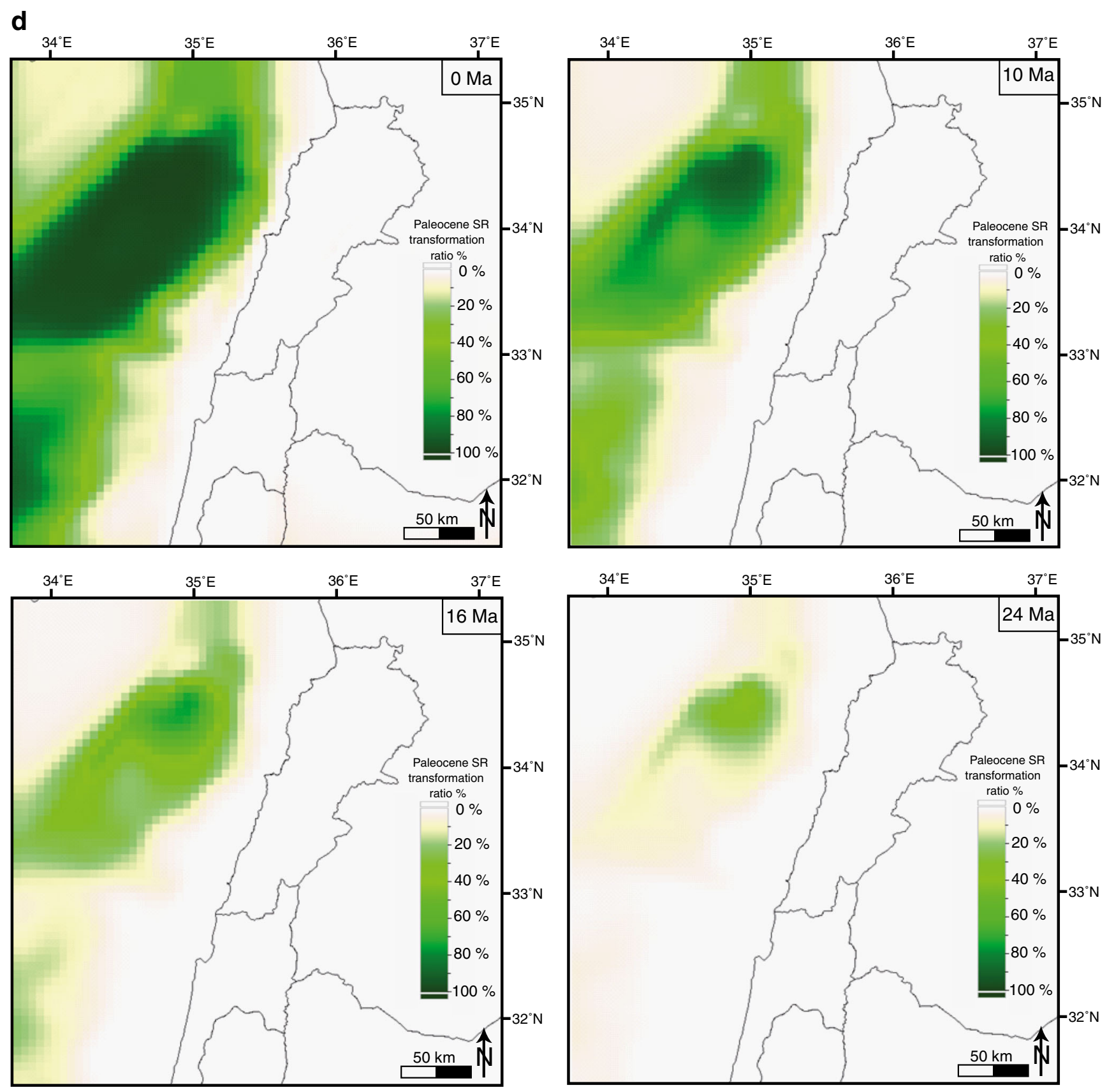

Fig. 9 (continued) 